\title{
Tolerance of Ambiguity, Development of Cognitive Models and Engineering Identity
}

\section{Dr. M. Javed Khan, Tuskegee University}

Dr. M. Javed Khan is Professor and Head of Aerospace Science Engineering Department at Tuskegee University. He received his Ph.D. in Aerospace Engineering from Texas A\&M University, M.S. in Aeronautical Engineering from the US Air Force Institute of Technology, and B.E. in Aerospace Engineering from the PAF College of Aeronautical Engineering. He also has served as Professor and Head of Aerospace Engineering Department at the National University of Science and Technology,Pakistan. His research interests include experimental aerodynamics, aircraft design and engineering education.

\section{Dr. Chadia A. Aji, Tuskegee University}

Chadia Affane Aji is a Professor in the Department of Mathematics at Tuskegee University. Dr. Aji received her Ph.D. and M.S. in Mathematics from Auburn University and a Bachelor in Chemical Engineering from Texas A\&M University. Her research interests lie in the areas of numerical analysis, computational applied mathematics, complex analysis, and on improving students' learning in STEM disciplines. Dr. Aji is involved in retention activities at Tuskegee University. She helps designing strategies to assist incoming freshmen cope with first year mathematics classes. She developed teaching modules to improve students' learning in mathematics using technology. 


\title{
Tolerance of Ambiguity, Development of Cognitive Models and Engineering Identity
}

\begin{abstract}
The cognitive models of students' perceptions of the real world lie on a spectrum spanning a dualistic understanding of the worldview on one end and a relativistic view on the other end. Students who are dualistic in their understanding of concepts have difficulty in solving problems which do not lend themselves to a well-defined single answer or solution. One would therefore assume that engineering students would rapidly develop a relativistic understanding of the solution space. It is also expected that this developmental process would also manifest itself in the strengthening of an engineering identity. The focus of the research presented in this paper is to explore the relationships of the cognitive models of the solution space, tolerance of ambiguity and the development of engineering identity. A cross-sectional study of the cognitive models of undergraduate students, their tolerance to ambiguity and perception of engineering identity was conducted at an historically black university. The modified Rydell-Rosen Ambiguity Tolerance (RRAT) instrument for tolerance of ambiguity and the Bateman-McDonald (BD) instrument for determining their location on the cognitive spectrum were used in this study. The students were also administered the Godwin Engineering Identity (GEI) survey. Data analysis indicated that students' tolerance of ambiguity increased on only few items of the RRAT instrument with the time spent in college. The analysis of the engineering identity indicated positive changes on several of the items of the instrument for the freshmen while reduction on some items of the GEI survey were observed. This research is supported by NSF Grant\# 1832041.
\end{abstract}

\section{Introduction}

It is expected that by 2025 the US will require an additional 3.5 million science, technology, engineering and mathematics (STEM) qualified persons to fill the growing need [1]. However, the challenge being faced is the retention and subsequent graduation of students in STEM fields, particularly in engineering. According to a 2017 report [2] by the American Society of Engineering Education (ASEE), there was a small (5\%) increase from 78\% (2003) to $82 \%$ (2014) in the firstyear persistence of White students. However, the persistence numbers remained flat at about $75 \%$ for African-American students. The ASEE report [2] also noted the 4-year and 6-year graduation rates in 2014 for white students to be $33 \%$ and $60 \%$ respectively, while for African-American students the rate was $20 \%$ and $38 \%$ respectively. Research on determining the reasons and designing empirically supported intervention strategies to increase retention and graduation rates in engineering has been prolific [3] - [7].

One of the several constructs that have been identified as having an impact on the academic success of undergraduate students is their professional identity. There is extensive research on identity and its development. Identity of an individual consists of several intersecting sub-identities such as a personal identity (individual characteristics), social identity (group characteristics, cultural characteristics), and professional identity. Bragg [8] defines professional identity as "internalization of the norms of the profession into the individual's self-image ... [and] the acquisition of the specific competence in knowledge and skills, autonomy of judgment, and responsibility and commitment of the profession" as cited by Lidell et al. [9]. Ibarra [10] has 
summed up the definition of Schein [11] as professional identity to be the "relatively stable and enduring constellation of attributes, values, motives, and experiences in terms of which people define themselves in a professional role". The adaptability and mutability of professional identity early in one's career has been alluded to by Ibarra [10]. External validation by other professionals in the field is an important element of professional identity [12, page 68]. Carlone and Johnson [13] noted competence, performance and recognition as dimensions of professional identity.

Professional identity development has been studied in context of various professions such as medicine [14], health care [15], pharmacy [16], and higher education [8, 9]. There is a reasonable body of literature that focuses specifically on engineering identity, its development and impact on engineering students. Dehing, Baartman and Joachems [17] have proposed two main groups of theories on engineering identity development; one that emphasized professional apprenticeship, and the other, participating and experimenting with professional roles. It has also been reported that low identity level students increased their engineering identity, and students with high levels of engineering identity did not gain as much from the work place learning [18]. Factors such as making competent design decisions, working with others to share ideas and accepting responsibility had been observed to impact the development of an engineering identity [19], [20]. An exhaustive literature review pertinent to engineering identity can be found in [21] and [22]. Among other observations such as standardized use of the construct, it was noted in [21] that engineering identity "has not been conceptualized or measured directly to date".

There are limited studies exploring the relationship between engineering identity, the 'tolerance of ambiguity', and 'intellectual/cognitive models' of undergraduate students. Ambiguity has been defined as 'lack of information to understand the situation or the possible outcomes', and tolerance of ambiguity as "the way an individual (or group) perceives and processes information about ambiguous situations or stimuli when confronted by an array of unfamiliar, complex or incongruent clues" [23], [24]. It was proposed by Perry [25] that the intellectual models of college students lie on spectrum spanning a dualistic understanding (position 1) of the world to a more nuanced relativistic world view (position 9). In light of what engineers are expected to do, one could therefore safely predict that the experience of an engineering curriculum should develop students' tolerance of an ambiguous problem space, and acceptance of a solution space that admits multiple solutions. However, this does not seem to be the case. It has been shown [26], [27] as cited in [28] that undergraduate engineering students did not develop beyond an average of 2.8 on the Perry's scale. This is in contrast with the result of Perry's sample of liberal arts students who were in position 7 or 8 at graduation [25]. Bateman and Donald [29] measured the location of the intellectual/cognitive models of undergraduate students and reported that the students preferred agreement with statements that were toward higher level of intellectual development.

This paper provides exploratory data and understanding of how undergraduate engineering students progressed in developing their engineering identity, tolerance of ambiguity, and intellectual models.

\section{Method}

The study was a between-group quasi-experimental design. The data was collected from a crosssection of undergraduate engineering students consisting of freshmen, sophomores, juniors, and seniors at an HBCU through various validated survey instruments. The number of respondents (N) 
are indicated in the various charts and tables. The surveys were administered online as Google Forms. Response to the surveys was voluntary. The data on engineering identity were collected using the Godwin Engineering Identity (GEI) instrument [30]. This is an 11-item instrument that measures three dimensions of engineering identity (Recognition, Interest, Performance). The tolerance of ambiguity was measured using the modified 20-item Rydel-Rosen Ambiguity Tolerance (RRAT) instrument [31]. The location of the students on intellectual spectrum was measured using Bateman-Donald (BD) survey instrument [30] which consists of 16-items, with 4items for each of the four dimensions (Dualism, Multiplicity, Relativity, Commitment). All instruments were 5-pont Likert scale surveys (5-strongly agree, 4-Agree, 3-Neutral, 2-Disagree, 1-Strongly disagree).

\section{Results and Discussion}

The GEI data was analyzed using independent-sample two-tailed t-tests $(\mathrm{p}<0.05)$ and a one-way ANOVA. No statistically significant differences were observed between the students of the various academic standings.

The data was then analyzed to identify trends. The GEI survey results are shown in Table I, and Fig.la for all participants, males and females $(\mathrm{N}=138)$. The mean of responses of male students $(\mathrm{N}=109)$ are shown in Table I(b) and Fig. 1b. It was observed (Table I) that the mean of the responses of freshmen were either equal to or higher than that of the seniors for all except three

\begin{tabular}{|l|c|c|c|c|}
\hline \multicolumn{1}{|c|}{ Mean by Academic Standing } & $\begin{array}{c}\text { Freshmen } \\
\mathrm{N}=95\end{array}$ & $\begin{array}{c}\text { Sophomores } \\
\mathrm{N}=15\end{array}$ & $\begin{array}{c}\text { Juniors } \\
\mathrm{N}=14\end{array}$ & $\begin{array}{c}\text { Seniors } \\
\mathrm{N}=14\end{array}$ \\
\hline 1. My parents see me as an engineer & 4.33 & 4.40 & 4.00 & 4.21 \\
\hline 2. My instructors see me as an engineer. & 3.91 & 3.60 & 3.71 & 3.79 \\
\hline 3. My peers see me as an engineer. & 4.00 & 3.80 & 4.14 & 4.00 \\
\hline 4. I am interested in learning more about engineering. & 4.52 & 4.33 & 4.29 & 4.86 \\
\hline 5. I enjoy learning engineering. & 4.40 & 4.07 & 4.36 & 4.36 \\
\hline 6. I find fulfillment in doing engineering. & 4.26 & 4.07 & 4.36 & 4.00 \\
\hline 7. I am confident that I can understand engineering in class. & 4.13 & 4.20 & 4.43 & 4.07 \\
\hline 8. I am confident that I can understand engineering outside of class. & 3.97 & 4.20 & 4.43 & 4.36 \\
\hline 9. I can do well on exams in engineering. & 4.05 & 4.07 & 4.36 & 3.93 \\
\hline 10. I understand concepts I am studying in engineering. & 4.08 & 3.93 & 4.43 & 4.07 \\
\hline 11. Others ask me for help in engineering/math subjects & 3.80 & 4.27 & 3.86 & 4.07 \\
\hline
\end{tabular}
statements which refer to interest (item \#4), confidence in learning outside the class (item \#8), and others asking for help (item \#11). When the data was analyzed for only male students (Table I), it was noted that on the average male freshmen were enjoying engineering (item \#5) more than male seniors. Additionally, the mean of the responses of male seniors (Table II) was

\begin{tabular}{|l|c|c|c|c|}
\hline \multicolumn{1}{|c|}{$\begin{array}{c}\text { Table I. Mean responses to GEI survey (all } \\
\text { Mean by Academic Standing }\end{array}$} & $\begin{array}{c}\text { Stetdentsophomores } \\
\mathrm{N}=76\end{array}$ & $\begin{array}{c}\text { Juniors } \\
\mathrm{N}=13\end{array}$ & $\begin{array}{c}\text { Seniors } \\
\mathrm{N}=10\end{array}$ \\
$\mathrm{~N}=10$ \\
\hline 1. My parents see me as an engineer & 4.36 & 4.38 & 3.70 & 4.00 \\
\hline 2. My instructors see me as an engineer. & 3.89 & 3.69 & 3.70 & 3.60 \\
\hline 3. My peers see me as an engineer. & 4.08 & 3.77 & 4.20 & 3.80 \\
\hline 4. I am interested in learning more about engineering. & 4.51 & 4.31 & 4.30 & 4.90 \\
\hline 5. I enjoy learning engineering. & 4.46 & 4.08 & 4.40 & 4.50 \\
\hline 6. I find fulfillment in doing engineering. & 4.33 & 4.08 & 4.40 & 4.00 \\
\hline 7. I am confident that I can understand engineering in class. & 4.18 & 4.23 & 4.20 & 3.90 \\
\hline 8. I am confident that I can understand engineering outside of class. & 4.07 & 4.23 & 4.30 & 4.40 \\
\hline 9. I can do well on exams in engineering. & 4.11 & 4.08 & 4.10 & 3.70 \\
\hline 10. I understand concepts I am studying in engineering. & 4.21 & 3.92 & 4.40 & 3.90 \\
\hline 11. Others ask me for help in engineering/math subjects & 3.88 & 4.23 & 3.70 & 3.90 \\
\hline
\end{tabular}
lower on seven of the eleven statements as compared to the combined average of male and female seniors

(Table I). This comparison

Table II. Mean responses to GEI survey (male students)

shows that even the though the number of female participants is low, it impacted the results in the sense that their engineering identity was stronger as indicated by these statements. 
The mean values of the responses to the GEI were plotted for all the participants (Fig. 1a) and for male participants (Fig. 1b). It was observed that the male students who had spent more time in college (more than a year) were less confident of recognition as engineers by their instructors (item \#2). The confidence of the male seniors in doing well in the exams (item \#9), and understanding engineering in class (item \#7) were lower as compared to the male students from lower academic standing.

In contrast, the male seniors indicated higher confidence in their understanding of engineering outside the class students (item \#8) as compared to the male students from lower academic standing.

Engineering Identity Survey (Total Participants $\mathrm{N}=138$ )

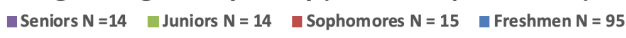

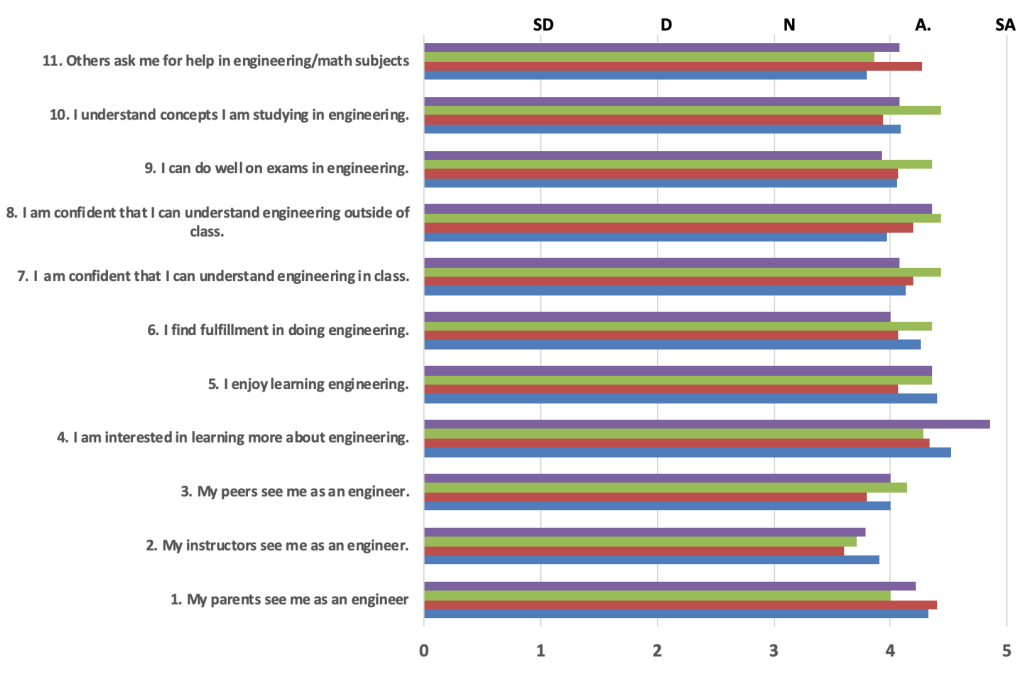

Figure 1a. Mean responses to GEI (all students)

The largest mean agreement of the male seniors was with the statement pertaining to interest in learning more about engineering (item \#4) in comparison to their responses to all other items (Fig. 1b). In fact, the average of the response of the seniors to item \#4 was the highest of all responses by all male students (Fig. 1b).

The responses to the GEI survey were compared by gender (Fig. 2). The means of the responses to seven of the eleven statements for males were higher except for two statements (item \#1, item \#2). The female students felt more recognized as engineers by the instructors and their parents.

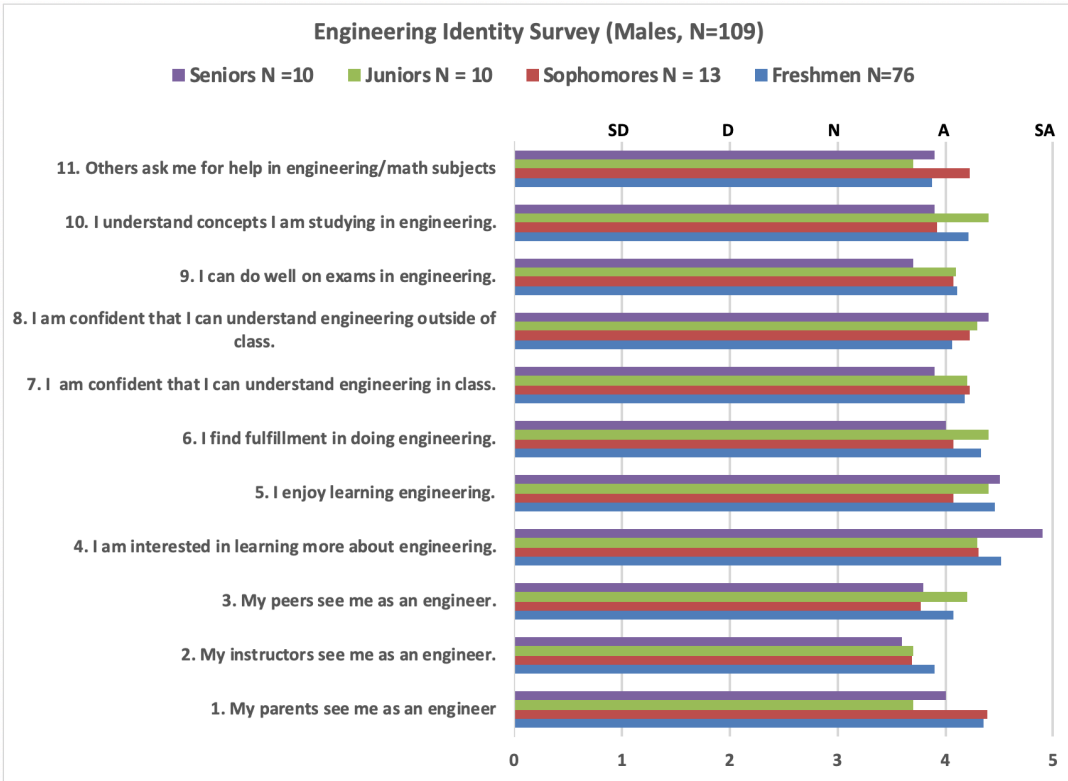

Figure 1b. Mean responses to GEI (male students)

The analysis of the data (Fig. 3a) by the three dimensions, D1: Recognition (items \#1, \#2, \#3), D2: Interest (items $\# 5, \# 5, \# 6$ ), and D3: Performance/Competence (items \# 9, \#10, \#11) for the male students provided additional insight into the engineering identity of students. These results show 
a reduction in the feeling of recognition with the time spent in college. As was observed previously, one of the factors impacting this dimension is the lower confidence of the male students in being seen as engineers by the instructors. A reduction in interest with time spent was also observed. The mean of the responses to the dimension of performance/competence was higher for the seniors as compared to the other male students. The combined data of female and male students (Fig. 3b) in comparison to Fig. 3a which is for only male students, indicates the impact of the responses of female students on the dimensions of interest, and recognition.

The analysis of the data (Fig. 3a) by the three dimensions, D1: Recognition (items \#1, \#2, \#3), D2: Interest (items $\# 4, \# 5, \# 6)$, and D3:

Performance/Competence (items \#7, \#8, \#9, \#10, \#11) for the male students provided additional insight into the engineering identity of students. These results show a reduction in the feeling of recognition with the time spent in college. As was observed previously, one of the factors impacting this dimension is the lower confidence of the male students in being seen as engineers by the instructors.

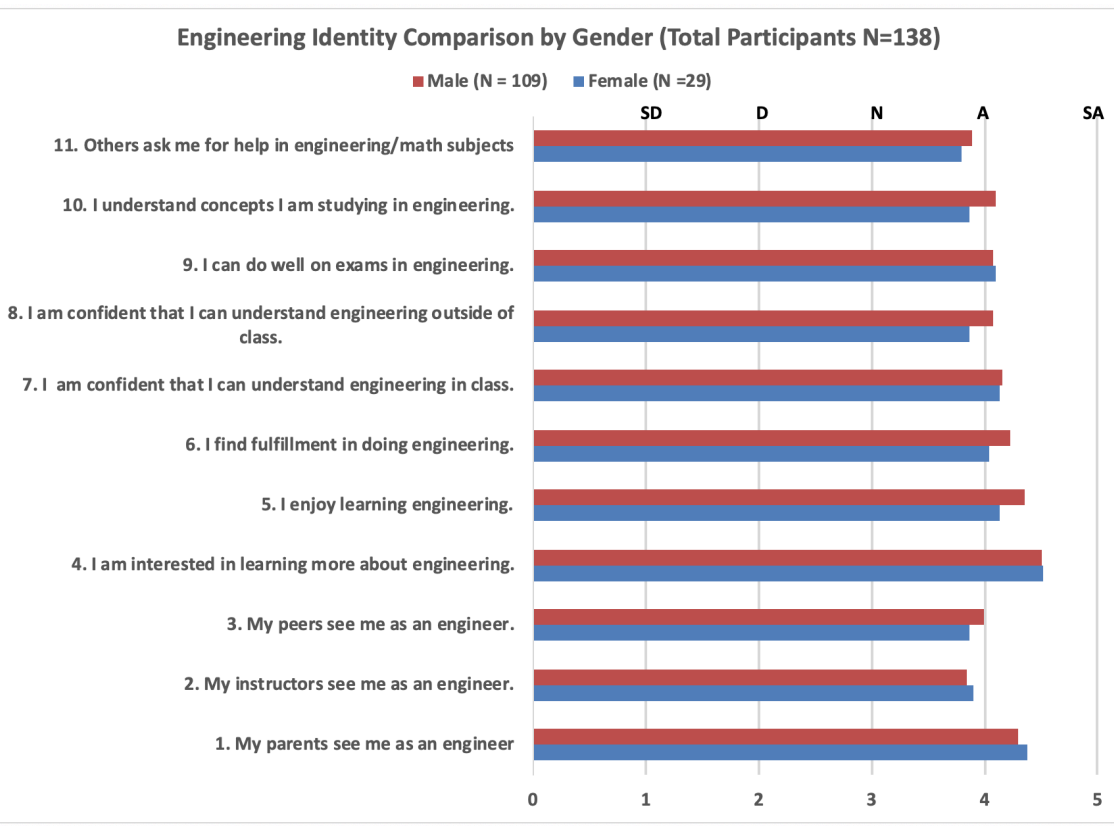

Figure 2. Mean responses to GEI by gender

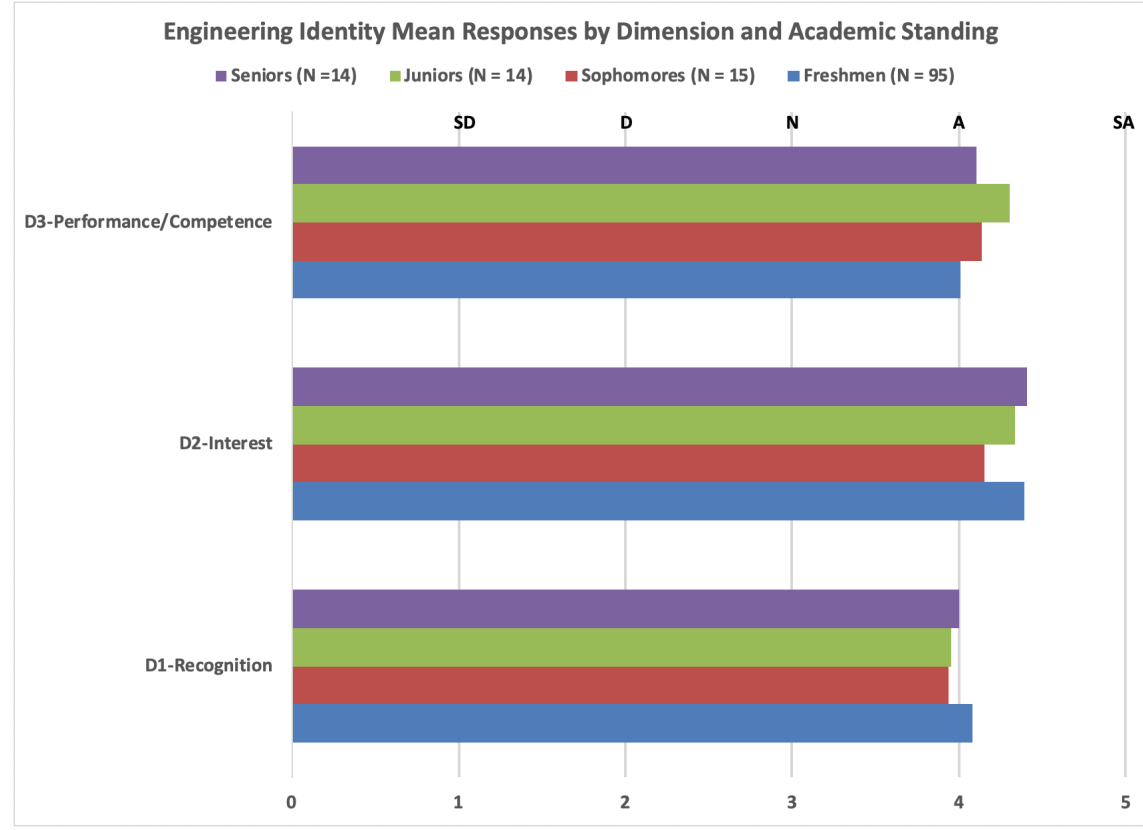

Figure 3a. Mean responses to GEI by Dimension (all students)

A reduction in interest with time spent was also observed. The mean of the responses to the 
performance/competence dimension was higher for the seniors as compared to the other male students. The combined data of female and male students (Fig. 3a) in comparison to Fig. $3 \mathrm{~b}$ which is for only male students, indicates the impact of the responses of female students on the dimensions of interest, and recognition.

As part of this study, the freshmen "Introduction to Aerospace Engineering" which is a one-credit hour course was redesigned in Fall 2019 to include hands-on activities such as paper aircraft competition, quadcopter programming, and a commercial aircraft passenger cabin layout design. The students enrolled in this course $(\mathrm{N}=16)$ were administered the GEI survey at the start of the semester and then at the end of semester. The averages of the pretest and posttest responses of the students to the GEI survey are given in Fig. 4. While there is no statistically significant $(\mathrm{p}<0.05)$ change between posttest and pretest, a positive change was registered (Fig $4 \mathrm{a}$ ). The analysis by dimension (Fig. 4b) clearly shows the impact of the intervention on the engineering identity of the students.

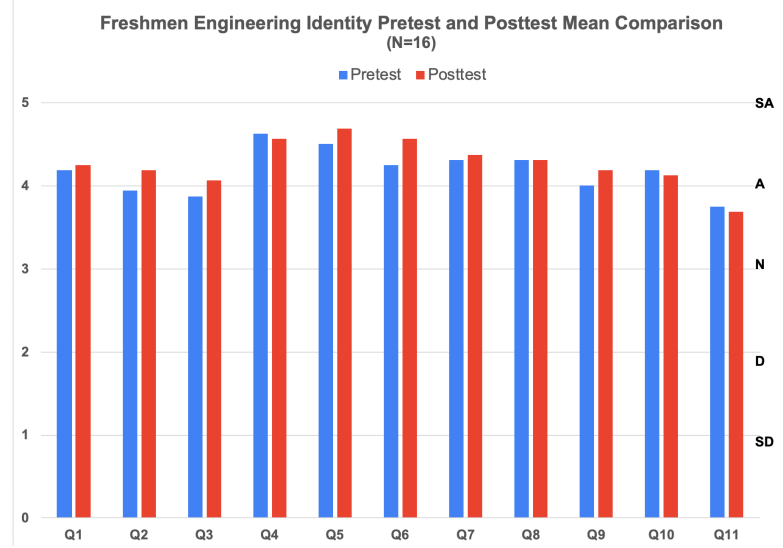

Figure 4a. Mean responses to GEI of freshmen

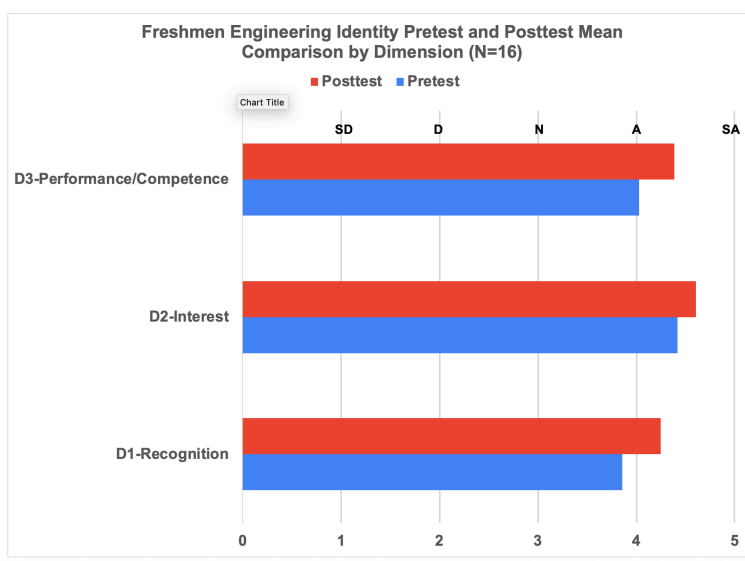

Figure $4 b$. Freshmen responses to GEI dimensions

The RRAT survey data is shown in Fig 5. Four out of twenty statements of the survey registered statistically significant changes between lower division (LD) students (freshmen and sophomores) and upper division (UD) students (juniors and seniors). These statements were: \#6 I get pretty anxious when I am in a social situation over which I have no control. 
$59 \%$ of the LD students disagreed with the statement (the correct response) and only 30\% UD students answered it correctly.

\#14 If I were a scientist, it would bother me that my work would never be completed (because science will always make new discoveries).

$39 \%$ of the LD students disagreed with the statement (the correct response), while $78 \%$ of the UD students disagreed with the statement.

\#17 Sometimes I rather enjoy going against the rules and doing things I am

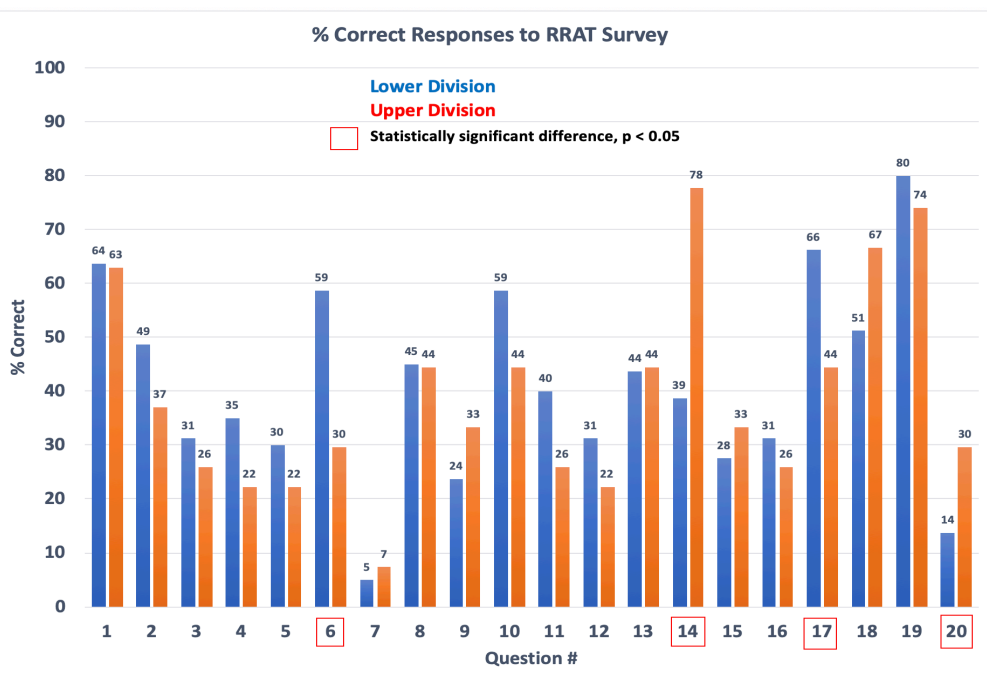

Figure 5. Comparison of RRAT responses not supposed to do.

$66 \%$ of the LD students responded correctly to this statement as compared to $44 \%$ of UD students.

\#20 Perfect balance is the essence of all good composition.

$14 \%$ of the LD students responded correctly to this statement while $30 \%$ of the UD responded correctly.

Of the 20 statements, a higher percentage of the LD students responded to 10 of the statements correctly while a higher percentage of UD students responded correctly to only 7 of the statements. An equal number of LD and UD students had correct responses to three of the statements.

An analysis was also done to determine if there is a correlation between the average of the responses to the engineering identity (GEI) and tolerance of ambiguity (RRAT) surveys. No correlation was observed between the GEI and the RRAT scores.

The data from the Bateman-Donald (BD) survey was administered to a group of engineering freshmen students $(\mathrm{N}=30)$. The survey measured the students' anchoring in zones of Duality, Multiplicity, Relativity and Commitment. The analysis of the data is given in Table III. The data suggested that the students were anchored in the Relativity and Commitment zones. This result is consistent with the observations of Bateman and Donald [31].

\begin{tabular}{|l|c|c|c|c|}
\hline & Duality & Multiplicity & Relativity & Commitment \\
\hline \% Agreement & 72 & 84 & 90 & 83 \\
\hline
\end{tabular}

Table III. Intellectual zones

\section{Conclusion and Future Work}

The study provided some interesting and useful insights into student learning. An important aspect that was identified was the students' reducing confidence in being recognized as an engineer by their instructors. The interest in learning engineering increased with time spent in college. The impact of incorporating hands-on activities in the introductory engineering class had a positive 
impact on the engineering identity of the students. The students' tolerance to ambiguity was a complex mix of socially and technically ambiguous situations. Students in the upper division were uncomfortable in a socially ambiguous situation as compared to students in the lower division. The data analysis did not suggest a correlation between the scores on the tolerance of ambiguity survey and the engineering identity survey. The freshmen students' intellectual models were toward the higher levels and not the simple dualistic level.

The surveys will be administered to additional (STEM and non-STEM) students, especially upper division students to have a better understanding of tolerance of ambiguity, development of cognitive model and engineering identity.

\section{Acknowledgement}

This work was supported by NSF Grant\# 1832041.

\section{References}

1. https://recruitingdaily.com/why-the-u-s-has-a-stem-shortage-and-how-we-fix-it-part-1/

2. https://ira.asee.org/wp-content/uploads/2017/07/2017-Engineering-by-the-Numbers-3.pdf

3. E. A. Kuley, S. Maw \& T. Fonstad (2015). Engineering Student Retention and Attrition Literature Review. Proc. 2015 Canadian Engineering Education Association (CEEA15) Conf. CEEA15; Paper 41 McMaster University; May 31 - June 3, 2015 https://pdfs.semanticscholar.org/f773/182a4313f3b229e7971557237a545f8c92ca.pdf

4. C. P. Veenstra, E. L. Dey \& G. D. Herrin (2009). A Model for Freshman Engineering Retention, Advances in Engineering Education, Winter 2009, Vol 1(3).

5. B. N. Geisinger \& D. R. Raman (2013). Why They Leave: Understanding Student Attrition from Engineering Majors. International Journal of Engineering Education Vol. 29, No. 4, pp. 914-925, 2013 https://lib.dr.iastate.edu/cgi/viewcontent.cgi?article $=1890 \&$ context $=$ abe eng pubs

6. Q. Li, H. Swaminathan \& J. Tang (2009). Development of a Classification System for Engineering Student Characteristics Affecting College Enrollment and Retention, Journal of Engineering Education, Vol 98(4), Oct. 2009, 361-376

7. G. Zhang, T. J. Anderson, M. W. Ohland \& B. R. Thorndyke (2004). Identifying Factors Influencing Engineering Student Graduation: A Longitudinal and Cross Institutional Study. Journal of Engineering Education, Vol 93(4), Oct. 2004, 313-320

8. A. K. Bragg (1976). The socialization process in higher education. ERIC/AAHE Research Report, no. 7. Washington, DC: American Association for Higher Education

9. D. L. Liddell, M. E. Wilson, K. Pasquesi, A. S. Hirschy \& K. M. Boyle (2014). "Development of Professional Identity Through Socialization in Graduate School. Higher Education and Student Affairs Faculty Publications. 12. https://scholarworks.bgsu.edu/hied pub/12

10. H. Ibarra (1999). Provisional selves: Experimenting with image and identity in professional adaptation. Administrative Science Quarterly, 44(4): 764-791.

11. E. H. Schein (1978). Career Dynamics: Matching Individual and Organizational Needs. Reading, MA: Addison-Wesley

12. D. Holland, W. Lachicotte Jr., D. Skinner, D. \& C. Cain, C. (1998). Identity and Agency in Cultural Worlds, Harvard University Press. Cambridge, Massachusetts. London, England. 1998 
13. H. B. Carlone \& A. Johnson (2007). Understanding the science experiences of successful women of color: Science identity as an analytic lens. Journal of Research in Science Teaching. 2007, Vol. 44(8):1187-1218

14. R. L. Cruess, S. R. Cruess S.R., J. D. Boudreau, L. Snell \& Y. Steinert (2014). Reframing medical education to support professional identity formation, Acad Med. Nov 2014, Vol. 89(11):1446-51. doi: 10.1097/ACM.0000000000000427

15. K. Adams, S. Hean, P. Sturgis \& J. M. Clark (2006). Investigating the Factors Influencing Professional Identity of First-Year Health and Social Care Students. Learning in Health and Social Care, Vol. 5(2), 55-68. doi:10.1111/j.1473-6861.2006.00119.x

16. A. J. M. Dehing, L. K. G. Baartman \& W. M. G. Jochems (2011). Mechanisms of students' engineering identity development during workplace learning in the bachelor curriculum. WEE2011, September 27-30, 2011, Lisbon, Portugal. Editors: Jorge Bernardino and José Carlos

17. M. F. Mylrea, S. Gupta \& B. D. Glass (2017). Developing Professional Identity in Undergraduate Pharmacy Students: A Role for Self-Determination Theory, Pharmacy (Basel). 2017 Mar 24; 5(2). pii: E16. doi: 10.3390/pharmacy5020016.

18. F. Dehing, W. Jochems, L. Baartman (2013). Development of an Engineering Identity in the Engineering Curriculum in Dutch Higher Education: An Exploratory Study from the Teaching Staff Perspective. European Journal of Engineering Education, Vol 38(1), 1-10 https://www.tandfonline.com/doi/full/10.11120/ened.2013.00007

19. H. Matusovich, B. E. Barry, K. L. Meyers \& R. Louis (2011). A Multi-Institution Comparison of Identity Development as an Engineer. $118^{\text {th }}$ ASEE Annual Conference Proceedings. Jun 26-29, 2011, Vancouver, BC, Canada.

20. K. L. Meyers, M. W. Ohland, A. L. Pawley, S. E. Silliman \& K. A. Smith (2012). Factors relating to engineering identity. Global Journal of Engineering Education, Vol 14(1), 2012

21. A. D. Patrick \& M. Borrego (2016). A Review of the Literature Relevant to Engineering Identity. $123^{\text {rd }}$ ASEE Annual Conference and Exposition, New Orleans, 26-29 Jun 2016

22. J. R. Morelock, J. R. (2017). A systematic literature review of engineering identity: definitions, factors, and interventions affecting development, and means of measurement. European Journal of Engineering Education, Vol. 42(6), 1240-1262, Feb 2017, http://www.tandfonline.com/eprint/uvMnAdrywrDPeXMbFicE/full, https://doi.org/10.1080/03043797.2017.1287664

23. A. Furnham \& J. Marks (2013). Tolerance of Ambiguity: A Review of the Recent Literature. Psychology, Vol. 4, 717-728. doi: 10.4236/psych.2013.49102

24. A. Furnham \& T. Ribchester (1995). Tolerance of ambiguity: A review of the concept, its measurement and applications. Current Psychology, Vol. 14, 179-199. doi:10.1007/BF02686907

25. W. G. Perry Jr. (1970). Forms of Intellectual and Ethical Development in the College Years: A Scheme. Holt, Rinehart and Winston, New York, 1970. Reprinted by Jossey-Bass Higher and Adult Education Series, 1998

26. P. Fitch \& R. S. Culver (1984). Educational activities to stimulate intellectual development in Perry's scheme. Proceedings ASEE Annual Conference, ASEE Washington, DC, 712-717, 1984.

27. M. Pavelich \& P. Fitch (1988). Measuring student's development using the Perry model, Proceedings ASEE Annual Conference, ASEE, Washington, DC, 668 - 672, 1988

28. https://engineering.purdue.edu/ChE/aboutus/publications/teaching_eng/chapter14.pdf 
29. Bateman, D. and Donald, J. G. (1987). Measuring the Intellectual Development of College Students: Testing a Theoretical Framework, The Canadian Journal of Higher Education, Vol. XVII-1, 1987, 28-45

30. A. Goodwin (2016). The Development of a Measure of Engineering Identity, ASEE 123rd Annual Conference and Exposition, 26-29 June, 2016, New Orleans, LA

31. McDonald, A. P. Jr. (1970). Revised Scale for Ambiguity Tolerance: Reliability and Validity, Psychological Reports, 1970, 26, 791-798. @ Psychological Reports http://www.sgha.net/library/pr0\%252E1970\%252E26\%252E3\%252E791.pdf 